\title{
Investigation of overvoltage on square, rectangular and L-shaped ground grids of high voltage substations by ATP/EMTP
}

\author{
Krung Luewattana ${ }^{1}$, Paweena Rattanasena ${ }^{2}$ \\ ${ }^{1}$ Sub-Department of Electrical Engineering, Faculty of Science and Technology, Phranakhon Si Ayutthaya Rajabhat \\ University, Ayutthaya, Thailand \\ ${ }^{2}$ Department of Applied Science, Faculty of Science and Technology, Phranakhon Si Ayutthaya Rajabhat University, \\ Ayutthaya, Thailand
}

\begin{abstract}
Article Info
Article history:

Received Aug 3, 2020

Revised Mar 11, 2021

Accepted Mar 23, 2021

\section{Keywords:}

Ground grid system

Ground potential rise

High voltage substation

Overvoltage

ABSTRACT

Ground grid system is important for preventing the hazardous effects of overvoltage in high voltage substations due to fault current perhaps from lightning strike or device malfunction. Therefore, this study aimed to investigate the effects of overvoltage on square, rectangular and L-shaped ground grids with ground rods being distributed in mesh-pattern by using alternate transients program/electromagnetic transients program (ATP/EMTP) program. The models were simulated in the cases that $25 \mathrm{kA}$ fault current being injected into the center or one of the corners of ground grids. The results showed that the highest level of overvoltage $(6.3349 \mathrm{kV})$ was detected at the corner of rectangular ground grid when the fault current was injected into its corner. However, the lowest level of overvoltage was found when the fault current was injected into the center of square ground grid. The results from this study indicated that ATP/EMTP program was useful for preliminary investigation of overvoltage on ground grids of different shapes. The obtained knowledge could be beneficial for further designing of ground grid systems of high voltage substations to receive the minimal damages due to fault current.
\end{abstract}

This is an open access article under the CC BY-SA license.

\section{Corresponding Author:}

Krung Luewattana

Department of Electrical Engineering

Faculty of Science and Technology

Phranakhon Si Ayutthaya Rajabhat University

Ayutthaya, Thailand

Email: zaraburi@yahoo.com

\section{INTRODUCTION}

At present, the transmission and distribution systems of electrical power between substations are extremely necessary for national development. These systems require the well-designed substations and ground grids to maximize their efficiency and reliability as well as to protect the working staff and important electrical devices that locating inside the substations or nearby proximity. Particularly, the reliable ground grid can play very important role in the case of overvoltage due to the natural disaster, lightning strike and switching device malfunction [1]. Since ground grid is a large system and too difficult to be created as demonstrative model under laboratory conditions, the computer programs hence become very useful and convenient for simulating such model. The computer programs, for example, current distribution in earth and grounding system (CDEGS), power system computer aided design (PSCAD), fast Fourier transformation 
(FFT), COMSOL, and alternate transient program/electromagnetic transients program (ATP/EMTP), have been applied with different advantages and disadvantages.

Initially, electromagnetic transients program (EMTP) was used for simulating the transmission line and ground grid models and then analyzing their lightning protection systems and dynamic behaviors during the occurrence of overvoltage on ground systems. The obtained results of this study were compared with the calculated ground potential rise (GPR). EMTP was also used for designing the lightning protection system of high voltage substation [2], [3]. In addition, the transient that occurred on ground grids and the frequency dependent characteristics of large ground grids were simulated based on the electromagnetic field theory approach by the computer model. This study also explored the effects of GPR, relative permeability of soil, and depth of ground grids buried in soil on the electromagnetic compatibility (EMC) in the case of lightning strike on ground grid [4]. Similar case of ground grid system that being injected with transient current has been simulated by the computer model and then endorsed by the experiments under laboratory conditions [5]. Furthermore, EMTP program was used for developing a model of double exponential time function from the inverse fast fourier transformation (IFFT) to analyze the response time of ground rod impulse and explore the dynamics between lightning protection and ground and the effects of charge that dispersing into the ground [6]. In addition, the effects of soil properties on impedance and transient responses of grounding electrode were investigated by the frequency-dependent soil model, which integrating the frequency-dependent soil electrical properties into the circuit model of grounding electrode and measuring the voltage response of grounding electrode. Comparison was performed between the voltage responses of the grounding electrode occurred in the circuit model and that in the electromagnetic model, which showing that the voltage peaks and the wave shapes obtained from these two models were very similar with less than $1 \%$ difference [7]. Furthermore, power system computer aided design (PSCAD) and current distribution, electromagnetic interference, grounding and soil structure analysis (CDEGS) programs were applied for investigating the possible severity of lightning strike on transmission line tower and nearby gas pipeline. However, CDEGS program was found to illustrate the effects of soil structure on induced voltage more accurately. Since CDEGS could show the results in three-dimensional (3D) illustrations and perform integration of frequency dependent soil electrical properties in grounding electrode circuit model, it was therefore used for examining the impacts of different soil resistivity levels, conductor materials, lightning impulse voltage front time waveforms, and soil profiles (uniform, 2-layer, and 3-layer) [8]-[12]. Interestingly, the use of CDEGS program could help to create the $3 \mathrm{D}$ plots of power plant's grounding system that was struck by lightning current and illustrate that the scalar potentials and electric fields were seriously affected [13]. In addition, the electrical transient analyzer program (ETAP) was used to optimize the similar parameters, especially the conductors' types, lengths, depths, and sizes [14]-[16].

In this study, the objective was to use ATP/EMTP for exploring the effects of overvoltage on three different ground grids (square, rectangular, and L-shaped ground grids with the same size of $324 \mathrm{~m}^{2}$ ) of high voltage substation. This is because ATP/EMTP is a convenient and simple program with ease of access that can help to preliminarily investigate the effects of overvoltage on various spots of ground grids with different shapes. The ground grids were designed according to the IEEE 80-2000 standard and therefore the obtained knowledge may be useful for designing the shape of ground grid that could protect the electrical equipment and ensure the safety of personnel inside the substation against electric shocks. This study may also provide the basic knowledge for further analysis by other advanced programs, and this could also help to understand which spots of substation that were minimally affected by overvoltage and should be used for placing the important electrical equipment [17]-[20].

This paper is organized is being as: Section 2 presents the designs of ground grid models and simulation process. The levels of overvoltage from simulations were presented and compared with the calculated GPR in section 3. Finally, section 4 presents the conclusions and reference list.

\section{RESEARCH METHOD}

\subsection{Designs of ground grid systems of high voltage substation}

Firstly, three models of ground grid systems of high voltage substation were designed, including square with the dimension of $18 \times 18 \mathrm{~m}$, rectangular of $27 \times 12 \mathrm{~m}$, and L-shaped of $18 \times 12+12 \times 9 \mathrm{~m}$, with the equal size of $324 \mathrm{~m}^{2}$. Even though these three models had different shapes, each of them was equipped with 24 ground rods distributed in mesh-pattern and had the same important parameters according to the standard of IEEE Std. 80-2000 [21] as shown in Figure 1.

\subsection{Devices and parameters for simulation by ATP/EMTP program}

Next, the devices of ground grids were determined by ATP/EMTP program. Initially, the grid conductor was chosen by the command 'Line/Cable' followed by 'RLC Pi-equiv'. Then, ground rod was 
selected by the command 'branch linear' followed by 'resistor'. Subsequently, the current sources for injecting fault current into the ground grid system was selected by the command 'Heidler type 15'. Finally, all these devices were connected together to create the models of square, rectangular and L-shaped ground grids as shown in the step 2.3. The parameters to be used in these models were shown in Table 1.

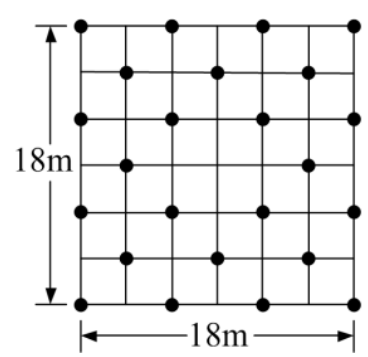

(a)

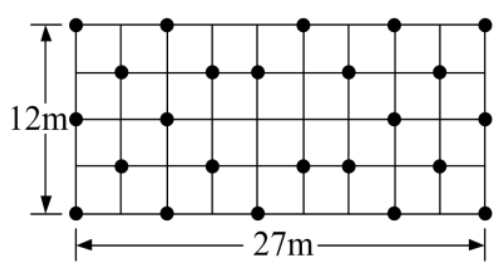

(b)

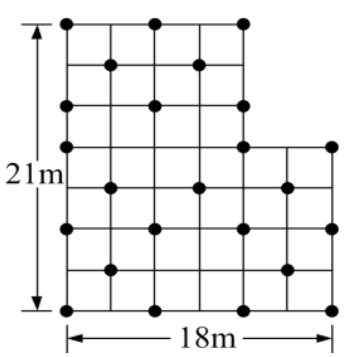

(c)

Figure 1. Three models of ground grid system, (a) square, (b) rectangular, and (c) L-shaped

Table 1. Parameters for ground grid models

\begin{tabular}{ccc}
\hline Parameter & Value & Unit \\
\hline Resistivity & $1.7 \times 10^{-8}$ & $\Omega-\mathrm{m}$ \\
Cross sectional area of conductor & 95 & $\mathrm{~mm}^{2}$ \\
Resistance & $5.3685 \times 10^{-4}$ & $\Omega-\mathrm{m}$ \\
Depth of ground rods & 0.5 & $\mathrm{~m}$ \\
Span length of grid conductor & 3 & $\mathrm{~m}$ \\
Inductance & 1620.2087 & $\mathrm{mH} / \mathrm{m}$ \\
Earth permittivity & $8 \times 10^{-11}$ & $\mathrm{~F} / \mathrm{m}$ \\
Capacitance & $4.44387 \times 10^{-4}$ & $\mu \mathrm{F} / \mathrm{m}$ \\
Soil resistivity & 10 & $\Omega-\mathrm{m}$ \\
Length of ground rod & 3 & $\mathrm{~m}$ \\
Diameter of ground rod & 16 & $\mathrm{~mm}$ \\
Resistance of ground rod & 3.508 & $\Omega-\mathrm{m}$ \\
Fault current & 25 & $\mathrm{kA}$ \\
\hline
\end{tabular}

\subsection{Square, rectangular and L-shaped ground grids with ground rods distributed in mesh-pattern}

From previous step, the devices and parameters were determined for creating the square, rectangular and L-shaped ground grid models with ground rods distributed in mesh-pattern as shown in Figures 2-4. Next, these models were used for simulating the case of $25 \mathrm{kA}$-fault current being injected directly into the center or one of the corners of ground grid systems, example was shown in Figure 2. Subsequently, levels of overvoltage measured on a diagonal line and at a corner of ground grids were recorded and plotted as shown in the section 3 .

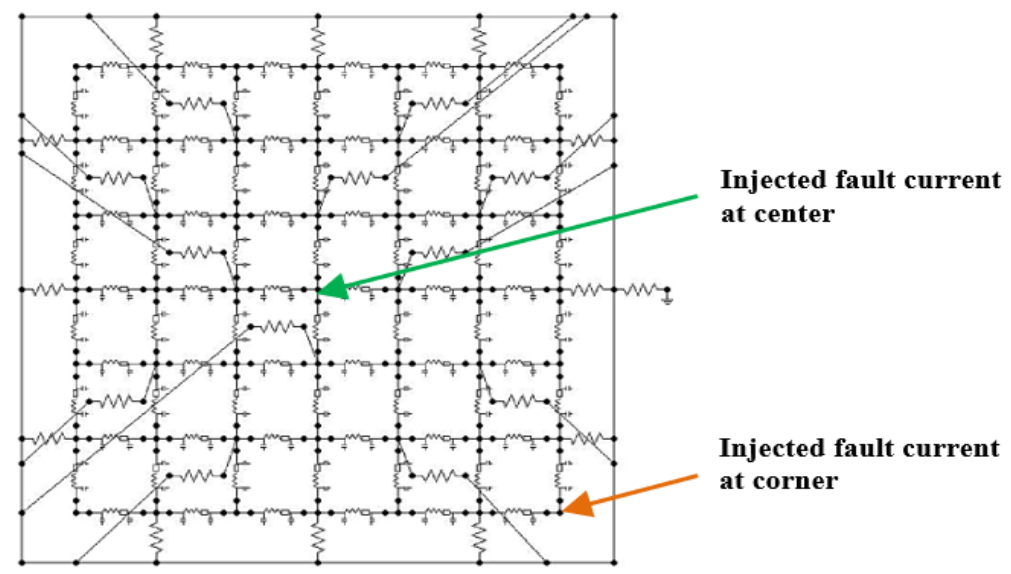

Figure 2. Model of square ground grid with ground rods distributed in mesh pattern for simulation by ATP/EMTP program 


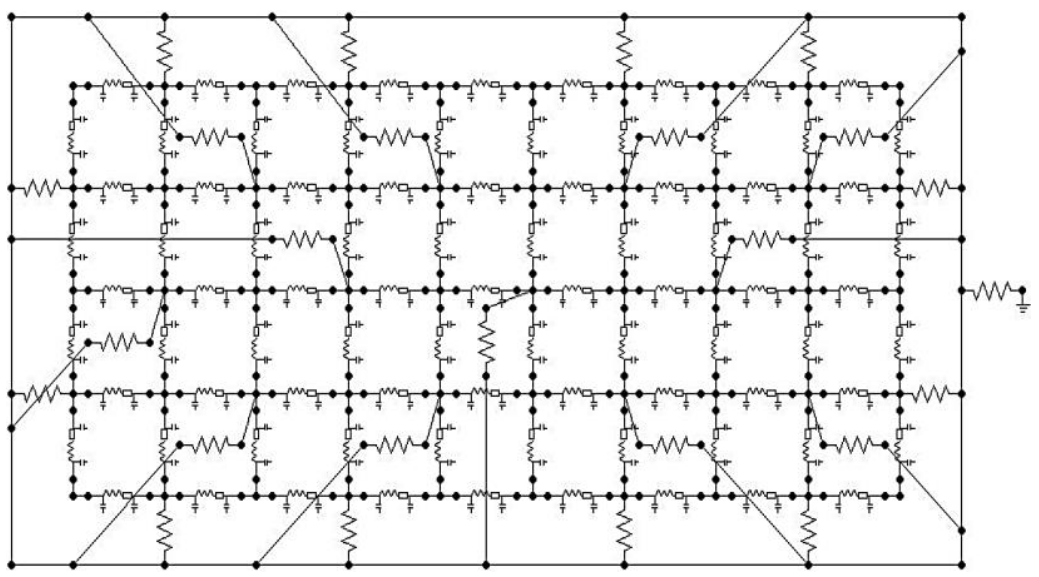

Figure 3. Model of rectangular ground grid with ground rods distributed in mesh-pattern for simulation by ATP/EMTP program

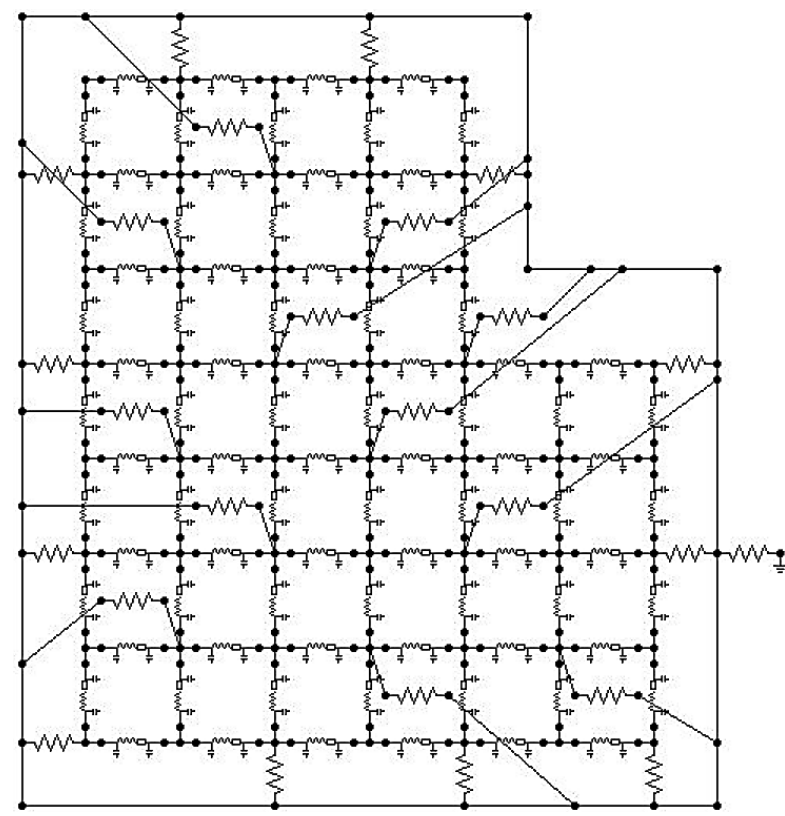

Figure 4. Model of L-shaped ground grid with ground rods distributed in mesh-pattern for simulation by ATP/EMTP program

\subsection{Equations for ground grid simulation}

The levels of maximum GPR of square, rectangular and L-shaped ground grids were calculated from the as described by [22]. Since the calculations of these cases gave only slightly different levels of GPR, the maximum GPR $(5.130 \mathrm{kV})$ was therefore used for comparing with the results obtained from simulations of three cases by using ATP/EMTP program according to IEEE Std. 80-2000 [21], [22].

\section{RESULTS AND DISCUSSION}

By ATP/EMTP program, the cases of fault current being injected into the center or one of the corners of each ground grid were simulated, and the levels of overvoltage on a diagonal line and at a corner of that ground grid were measured as shown in Figures 5 and 6 for square, Figures 7 and 8 for rectangular, Figures 9 and 10 for L-shaped ground grids. The levels of overvoltage from simulations of square, rectangular and L-shaped ground grids were then compared with calculated GPR as shown in Figure 11. In the case of square ground grid with ground rods distributed in mesh-pattern, the maximum overvoltage could be detected when the fault current was injected into the corner of ground grid. The maximum overvoltage 
measured on diagonal line and at corner were $5.8528 \mathrm{kV}$ Figure 6(a) and $5.9674 \mathrm{kV}$ Figure 6(b), which were higher than the calculated GPR $5.130 \mathrm{kV}$, Figure 11 for $14.09 \%$ and $16.32 \%$, respectively. For the case of rectangular and L-shaped ground grids, similar results of maximum overvoltage were detected when the fault current was injected into the corner of ground grid. For rectangular ground grid, when the fault current was injected into the corner, the maximum overvoltage measured on diagonal line and at corner were $6.2089 \mathrm{kV}$ Figure 8(a) and $6.3349 \mathrm{kV}$ Figure 8(b), which were higher than the calculated GPR for $21.03 \%$ and $23.48 \%$, respectively. Also, In the case of L-shaped ground grid, when the fault current was injected into the corner, the maximum overvoltage measured on diagonal line and at corner were 6.1407 Figure 10 (a) and $6.1808 \mathrm{kV}$ Figure 10(b), which were higher than the calculated GPR for $19.70 \%$ and $20.48 \%$, respectively.

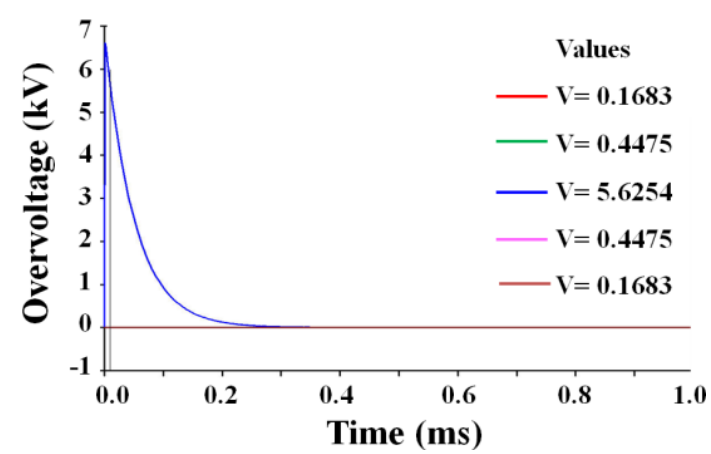

(a)

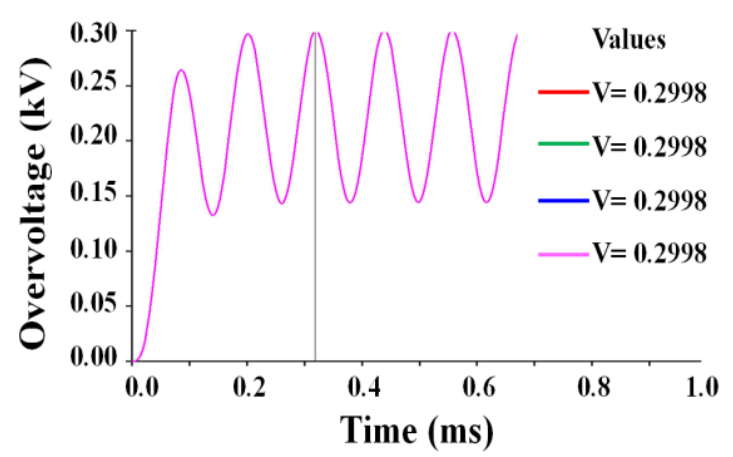

(b)

Figure 5. Voltage distribution; (a) on a diagonal line, (b) at a corner of square ground grid when the fault current being injected into the center of ground grid

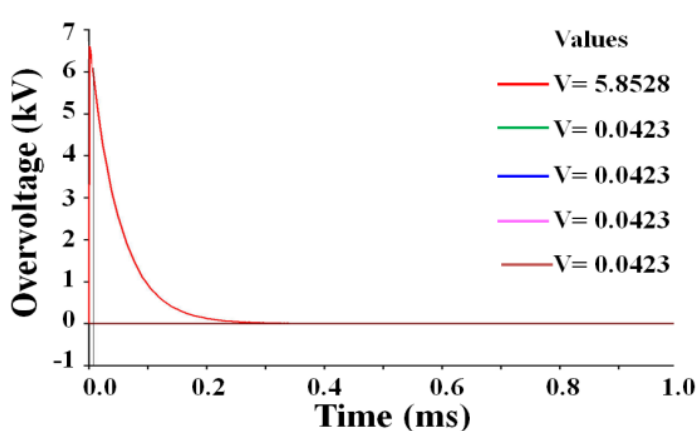

(a)

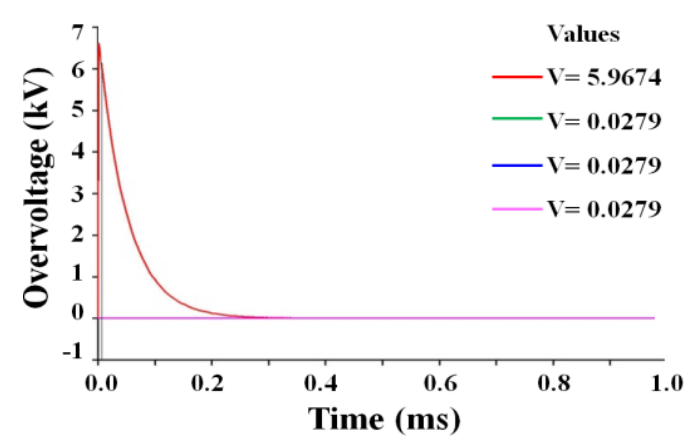

(b)

Figure 6. Voltage distribution; (a) on a diagonal line, (b) at a corner of square ground grid when the fault current being injected into the corner of ground grid

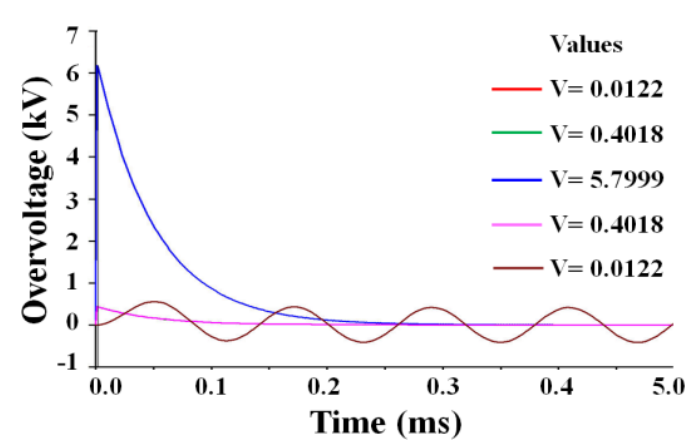

(a)

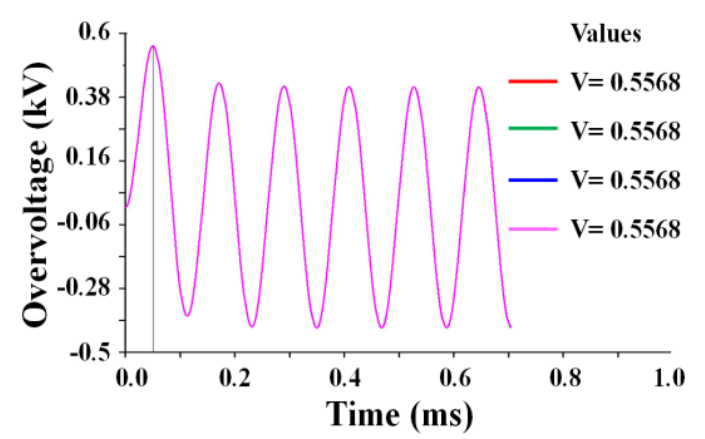

(b)

Figure 7. Voltage distribution; (a) on a diagonal line, (b) at a corner of rectangular ground grid when the fault current being injected into the center of ground grid 


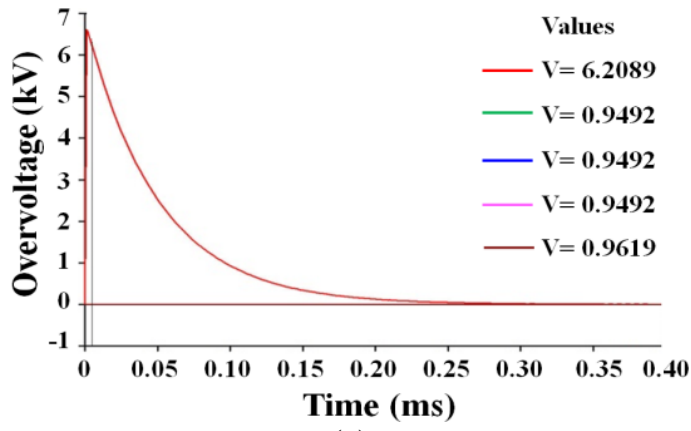

(a)

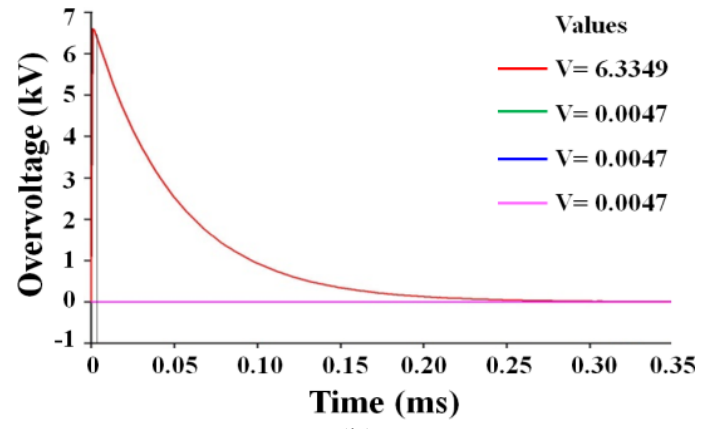

(b)

Figure 8. Voltage distribution; (a) on a diagonal line, (b) at a corner of rectangular ground grid when the fault current being injected into the corner of ground grid

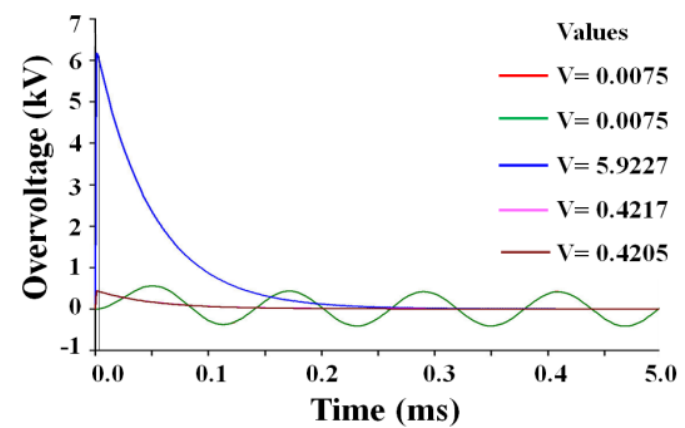

(a)

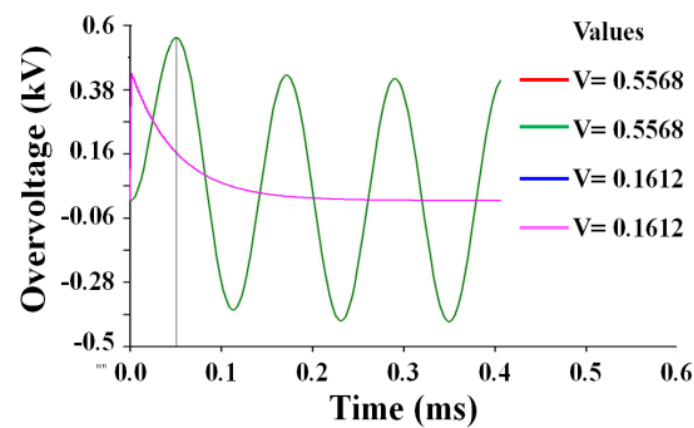

(b)

Figure 9. Voltage distribution; (a) on a diagonal line, (b) at a corner of L-shaped ground grid when the fault current being injected into the center of ground grid

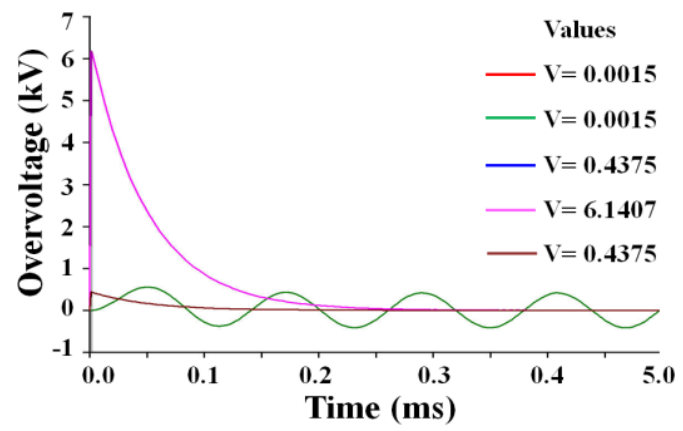

(a)

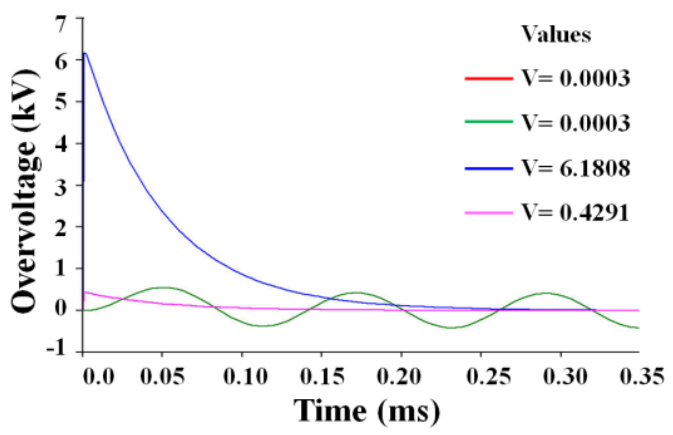

(b)

Figure 10. Voltage distribution; (a) on a diagonal line, (b) at a corner of L-shaped ground grid when the fault current being injected into the corner of ground grid

According to these three models, the square ground grid was found to have the lowest overvoltage. This may be because square shape is symmetrical, and when the fault current has flown through the conductor in the center of this ground grid system, the connecting points of system's intersection between ground grid and ground rods, which are symmetrically joined together by exothermic welding both horizontally and vertically, may help to release the fault current very rapidly in spherical radius. Consequently, the overvoltage occurring on square ground grid may return back to the surface of the earth at the levels lower than that of rectangular and L-shaped ground grids and quickly disperse into the earth. It could be shown in the case of injecting the fault current into the center of square ground grid and measuring the overvoltage on a diagonal line that resulting in the overvoltage of $5.6254 \mathrm{kV}$ Figure 5(a) which being lower than that of rectangular and L-shaped ground grids for $3.1 \%$ and $5.28 \%$, respectively. 


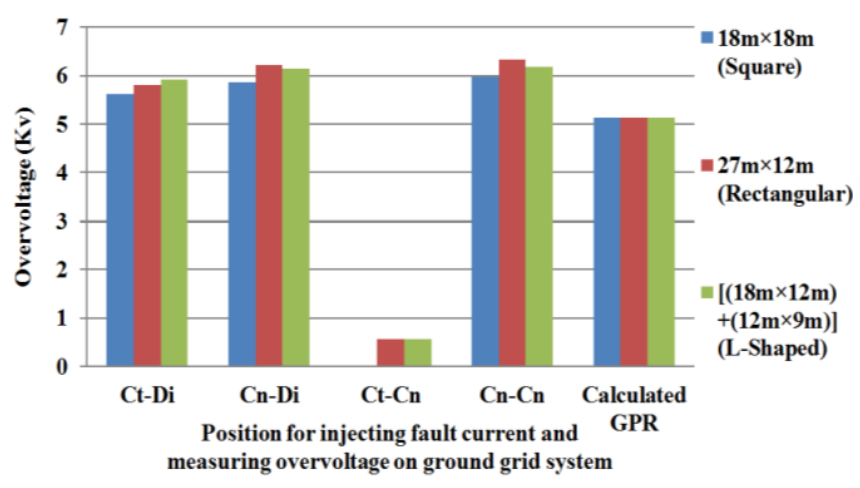

Figure 11. Comparison of overvoltage on three shapes of ground grids with calculated GPR. The first abbreviations were the spots for injecting fault current $(\mathrm{Ct}=$ center, $\mathrm{Cn}=$ corner $)$ and the second abbreviations were the spots for measuring overvoltage $(\mathrm{Di}=$ diagonal line, $\mathrm{Cn}=$ corner $)$

In contrast, the rectangular model was shown to have the highest overvoltage at $6.3349 \mathrm{kV}$ Figure $8(\mathrm{~b})$ in the case of injecting the fault current into the corner and measuring the overvoltage also at the corner. This may be because the rectangular shape is not symmetrical and, when the large amount of fault current has been injected into the corner, high intensity magnetic field may be induced. The reason may be due to that the conductor used in this study is copper, which is diamagnetic and highly capable of inducing magnetic field, especially at the corner of system's intersection where the ground grid and ground rods are joined together by exothermic welding in unsymmetrically pattern. The overvoltage may not well disperse to the underground earth, resulting in the overvoltage at levels higher than that of square and L-shaped ground grids for 5.8 and $2.43 \%$, respectively. However, the L-shaped ground grid was demonstrated to have average overvoltage when being compared with the other two ground grids. This may be due to that L-shaped ground grid has both symmetrical and unsymmetrical areas and therefore the overvoltage may disperse either effectively or poorly to the underground earth Figure 4.

From this study, the results may suggest that ATP/EMTP, a widely-used and simple program, can be beneficial for investigating the effects of overvoltage on ground grids of three different shapes, especially when the fault current was injected into the corner of rectangular ground grid that resulting in the highest overvoltage at the corner. There are the other programs that can be used for simulating the ground grid systems. For example, CDEGS, which is a specialized program with high performance, can define the type of laydown materials, simulate 2 layers of such materials, and also give the illustrative results in 2-and 3-D formats, but it has disadvantage in high cost and requirement for very effective computer resources and operating systems. Apart from that, the fast Fourier transformation (FFT) program has been used for calculating the frequency and time response values and illustrating the magnetic fields in the case of lightning strike on power plant's ground grid [13]. Moreover, PSCAD program has been applied for analyzing the effects of induced voltage due to lightning strike on overhead transmission line that affecting below gas pipeline [8]. However, both FFT and PSCAD have limitations in creating the models and determining the parameters. Currently, analysis of soil grounding materials with different levels of resistivity due to physical and chemical compositions may be performed by the advanced programs, such as COMSOL that use 3D finite element method (FEM) for simulating and displaying the ground grids and their electric and magnetic fields in 3D illustrations. COMSOL may also be useful for analyzing the effects of overvoltage on various designs of ground grids as well as the workers and equipment locating inside or nearby high voltage substation [7], [23]-[25], but it has drawbacks in its cost, requirement for highly effective computer resources and operating systems as well as time-consuming for generating the models and determining the parameters. From the results in this study, it would recommend ATP/EMTP to be used for preliminary investigation of the overvoltage on ground grids of different shapes and the obtained findings could be beneficial and critical for making decision in further investment for analysis by more advanced simulation programs.

\section{CONCLUSION}

The models created by ATP/EMTP program to investigate the effects of injected fault current and resulting overvoltage on ground grids of three different shapes (square, rectangular and L-shaped) showed that rectangular ground grid had the highest level of overvoltage, particularly at its corner, when the fault current was injected into its corner. On the contrary, square ground grid was found the have the lowest overvoltage, especially when the fault current was injected at its center. This study showed that ATP/EMTP

Investigation of overvoltage on square, rectangular and l-shaped ground grids of... (Krung Luewattana) 
is a simple simulation program with ease of accessibility and uses, particularly in creating the ground grid models and adding the important parameters. Moreover, it has benefits in less time-consuming and low cost for computer resources and operating systems. This study concluded that preliminary investigation of possible overvoltage on ground grid models of different shapes could be achieved by ATP/EMTP program, which may be suitable for further in-depth analysis by other advanced programs.

\section{REFERENCES}

[1] T. Chalardsakul, "Analysis overvoltage in the grounding system of high voltage substation by using ATP/EMTP program," Technology Promotion and InnoMag Magazine, vol. 202, pp. 88-93, 2008.

[2] F. E. Mentre and L. Grcev, "EMTP-based model for grounding system analysis," in IEEE Transactions on Power Delivery, vol. 9, no. 4, pp. 1838-1849, Oct. 1994, doi: 10.1109/61.329517.

[3] R. Shariatinasab and J. Gholinezhad, "The effect of grounding system modeling on lightning-related studies of transmission lines," Journal of Applied Research and Technology, vol. 15, no. 6, pp. 545-554, 2017, doi: 10.1016/j.jart.2017.06.003.

[4] L. D. Grcev and M. Heimbach, "Frequency dependent and transient characteristics of substation grounding systems," in IEEE Transactions on Power Delivery, vol. 12, no. 1, pp. 172-178, Jan. 1997, doi: 10.1109/61.568238.

[5] A. Geri, "Behaviour of grounding systems excited by high impulse currents: the model and its validation," in IEEE Transactions on Power Delivery, vol. 14, no. 3, pp. 1008-1017, July 1999, doi: 10.1109/61.772347.

[6] M. I. Lorentzou, N. D. Hatziargyriou, and B. C. Papadias, "Time domain analysis of grounding electrodes impulse response," in IEEE Transactions on Power Delivery, vol. 18, no. 2, pp. 517-524, April 2003, doi: 10.1109/TPWRD.2003.809686.

[7] Y. Liu, N. Theethayi, and R. Thottappillil, "An engineering model for transient analysis of grounding system under lightning strikes: nonuniform transmission-line approach," in IEEE Transactions on Power Delivery, vol. 20, no. 2, pp. 722-730, Apr. 2005, doi: 10.1109/TPWRD.2004.843437.

[8] A.I. Elgayar and Z. Abdul-Malek, "Induced voltages on a gas pipeline due to lightning strikes on nearby overhead transmission line," International Journal of Electrical and Computer Engineering, vol. 6, no. 2, pp. 495-503, 2016. doi: 10.11591/ijece.v6i2.9395.

[9] M. Adnan, Z. Abdul-Malek, N. S. M. Din, M. I. Jambak, Z. Nawawi, M. A. B. Sidik, "Effect of Lightning impulse front time on substation grounding system performance," Indonesian Journal of Electrical Engineering and Computer Science, vol. 20, no. 2, pp. 569-574, 2020, doi: 10.11591/ijeecs.v20.i2.pp569-574.

[10] Z. Abdul-Malek, M. S. A. Yaman, M. Adnan, "Effects of soil profile on the transient performance of substation grounding system," Indonesian Journal of Electrical Engineering and Computer Science, vol. 20, no. 2, pp. 870-877, 2020, doi: 10.11591/ijeecs.v20.i2.pp870-877.

[11] S. Nikolovski, G. Knezevic, and Z. Baus, "Assessment of step and touch voltages for different multilayer soil models of complex grounding grid," International Journal of Electrical and Computer Engineering, vol. 6, no. 4, pp. 1441-1455, 2016, doi: 10.11591/ijece.v6i4.pp1441-1455.

[12] M. Mokhtari, Z. Abdul-Malek, and C. L. Wooi, "Integration of frequency dependent soil electrical properties in grounding electrode circuit model," International Journal of Electrical and Computer Engineering, vol. 6, no. 2, pp. 792-799, 2016, doi: 10.11591/ijece.v6i2.pp792-799.

[13] S. N. Nikolovski, Z. Baus, and G. Knežević, "Frequency and time response of power plant grounding system exposed to lightning strike," International Journal of Electrical and Computer Engineering, vol. 6, no. 2, pp. 512525, 2016, doi: 10.11591/ijece.v6i1.9356.

[14] N. M. Tabatabaei and S. R. Mortezaeei, "Design of grounding systems in substation by ETAP intelligent software," International Journal on Technical and Physical Problems of Engineering, vol. 2, pp. 45-49, 2010.

[15] D. Prasad and H. C. Sharma, "Designing of Grounding System for High Voltage Substation," International Journal of Engineering and Advanced Technology, vol. 2, pp. 61-65, 2013.

[16] M. U. Aslam, M. U. Cheema, M. B. Cheema, and M. Samran, "Design analysis and optimization of ground grid mesh of extra high voltage substation using an intelligent software," 2014 The 1st International Conference on Information Technology, Computer, and Electrical Engineering, Semarang, Indonesia, 2014, pp. 339-345, doi: 10.1109/ICITACEE.2014.7065768.

[17] S. G. Farkoush, A. Wadood, T. Khurshaid, C. Kim, M. Irfan, and S. Rhee, "Reducing the Effect of Lightning on Step and Touch Voltages in a Grounding Grid Using a Nature-Inspired Genetic Algorithm With ATP-EMTP," in IEEE Access, vol. 7, pp. 81903-81910, 2019, doi: 10.1109/ACCESS.2019.2923656.

[18] H. N. Amadi, "Design of grounding system for A.C. substations with critical consideration of the mesh, touch and step potentials," European Journal of Engineering and Technology, vol. 5, no. 4, pp. 44-57, 2017.

[19] D. D. Vuckovic, N. N. Cvetkovic, and M. S. Stojanovic, "Study on a standard for grounding systems realization," Serbian Journal of Electrical Engineering, vol. 9, pp. 393-401, 2012, doi: 10.2298/SJEE1203393V.

[20] A. Phayomhom, S. Sirisumrannukul, and T. Kasirawat, "Safety design of ground grid in distribution substation: Case study of metropolitan electricity authority's system," GMSARN International Journal, vol. 4, pp. 67-74, 2010.

[21] An American National Standard, "IEEE guide for safety in AC substation grounding," in IEEE Std 80-2000, pp.1-192, 4 Aug. 2000, doi: 10.1109/IEEESTD.2000.91902.

[22] A. B. Patel and K. Velani, "Digital application for grounding grid design calculations of substation," 2017 Innovations in Power and Advanced Computing Technologies (i-PACT), Vellore, 2017, pp. 1-6, doi: 10.1109/IPACT.2017.8244947. 
[23] N. A. M. Hasni, R. Abd-Rahman, H. Ahmad, N. A. M. Jamail, M. S. Kamaruddin, and S. S. Ridzwan, "Investigation of potential grounding compound for portable applications," International Journal of Electrical and Computer Engineering, vol. 7, no. 6, pp. 3140-3146, 2017, doi: 10.11591/ijece.v7i6.pp3140-3146.

[24] A. J. L. M. Siang, E. H. Sfoog, N. Naji, S. S. Yi, N. A. A. Guntor, and J. Prasetijo, "Ground improvement using granular pile anchor system resistance to heave and uplift pressure," Indonesian Journal of Electrical Engineering and Computer Science, vol. 19, no. 1, pp. 403-411, 2020, doi: 10.11591/ijeecs.v19.11.pp403-411.

[25] A. A. Salem, R. Abd-Rahman, M. S. Kamarudin, H. Ahmed, and N. A. M. Jamail, "The effect of insulator geometrical profile on electric field distributions," Indonesian Journal of Electrical Engineering and Computer Science, vol. 14, no. 2, pp. 618-627, 2019, doi: 10.11591/ijeecs.v14.i2.pp618-627.

\section{BIBLIOGRAPHIES OF AUTHORS}

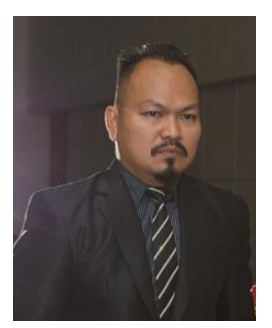

Krung Luewattana graduated B.Eng., M.Eng., and Ph.D. degrees in Electrical Engineering (with emphasis on Electrical Power Engineering). His research interests include high voltage, engineering and insulation, electrical grounding systems, power engineering and power systems, electromagnetic compatibility, transient in power system and renewable/alternative energy.

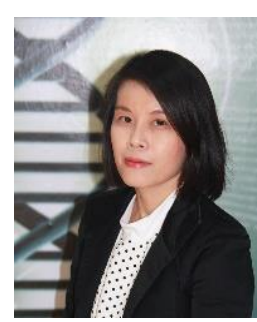

Paweena Rattanasena graduated B.Sc. in Microbiology (Chulalongkorn University, Thailand), M.Sc. in Tropical Infectious Diseases and Ph.D. in Tropical Health (both degrees from the University of Queensland, Australia). Her research interests include public health and safety, infectious diseases, and biotechnology. 